\title{
YELLOW KID, O MOLEQUE QUE NÃO ERA AMARELO
}

\begin{abstract}
A história em quadrinhos não foi criação de norte-americanos; uma galeria de artistas e desenhistas, incluindo nosso Ângelo Agostini, os precederam
\end{abstract}

A personagem do Yellow Kid alcançou uma importância de âmbito internacional. Desde 1995 a imprensa já lhe presta homenagens de centenário, com grande estardalhaço e foguetório - o nascimento do mito.

Moleque Amarelo passou a ser o marco da criação do mundo novo das histórias em quadrinhos: "Exatamente no dia 5 de maio de 1895 , um domingo", confirmam com segurança os historiadores ${ }^{1}$. Um domingo, exatamente o primeiro dia da Criação, como ensina a sagrada Bíblia.

"Nesse dia histórico", os fãs deslumbrados com fato tão grandioso, só comparável ao ato divino, clamam em coro: "No princípio, era o Amarelo", o Moleque, sacramentando, nesta hiperbólica paráfrase ao Livro dos Livros, a História da História em Quadrinhos: In principio erat Verbum ${ }^{2}$, a Palavra Divina.

\section{O AUTOR}

\section{Antônio Luís Cagnin}

Professor Doutor do Departamento de Cinema, Rádio e Televisão da ECA-USP. Autor de Os Quadrinhos.
Os Estados Unidos foram o palco do memorável acontecimento. Nas portas da passagem para o século XX, época de profundas mudanças na sociedade americana: a grande guerra contra monopólios e trustes; o nouveau riche e a plutocracia ianque; Roosevelt; a grande imprensa; a explosão tecnológica; a maravilha do telefone a manivela; a mágica da luz elétrica e da máquina falante com o seu frágil cilindro de cera; os carros sem cavalos abrindo caminho para os automóveis; o avião. Sobretudo, a época da emigração européia: irlandeses, alemães, russos, suecos, italianos; católicos e judeus - cujos estranhos costumes e sotaques eram as delícias dos comediantes de vaudeville; todos no grande e borbulhante cadinho em que se formou o modo de ser americano.

Era este o guisado cultural que nutriu a nova forma de arte americana: o comic strip, como é lá conhecido. Esta é a constatação de William Laas na Saturday Review of Litterature (Sábado Revista de Literatura), que assim confirmou com orgulho: o comic strip foi o mais vivo rebento de nossa turbulenta civilização. A América e o comic strip foram feitos um para o outro ${ }^{3}$.

1. MOYA, Álvaro de. História da História em Quadrinhos. São Paulo: Brasiliense, 1993, p.18.

2. "No princípio era o Verbo". Frase biblica do Apocalipse, de São João Evangelista: João, I, I.

3. ROBINSON, Jerry. The Comics, an Ilustrated History of Comics Strip Art. (Tiras de humor, uma história ilustrada da arte das tiras de humor) New York: Putnam's Sons, 1974. Jerry Robinson, escritor/caricaturista de antiga cepa, de irreverente sátira política e social, trabalhou no Chicago Tribune-New York News Syndicate e New York Daily News. Foi presidente da National Cartoonist Society, diretor da American Association of Editorial Cartoonists, diretor consultor da Graham Gallery de Nova Iorque, onde criou o Cartoon \& Comic Strip Art, em 1972; professor de jornalismo gráfico, por 10 anos, na School of Visual Arts. E, o que interessa principalmente aos quadrinheiros, foi o criador de Robin, o companheiro de Batman. 


\section{AMARELO, POR ACASO}

Todos os ingredientes essenciais dos quadrinhos estavam ali, envolvendo séculos das mais diversas sociedades e culturas, esperando apenas pela correta combinação de tempo, lugar e modelo, pontifica Jerry Robinson, com ufania ${ }^{4}$. Dois atores, Joseph Pulitzer e William Randolplh Hearst, os gigantes da imprensa, encenaram o grande ato, cuja rivalidade profunda serviu de catalisador para a surgimento do comic strip.

O drama começou em 1893, quando Pulitzer comprou uma rotativa Hoe a quatro cores, com a intenção de imprimir as mais famosas obras de arte no suplemento dominical do seu New York World. Não teve sucesso, e a rotativa foi usada, ao invés, para reproduzir grandes desenhos. Morril Goddard, editor da página dominical, defendeu ferrenhamente aproveitar o equipamento para a arte

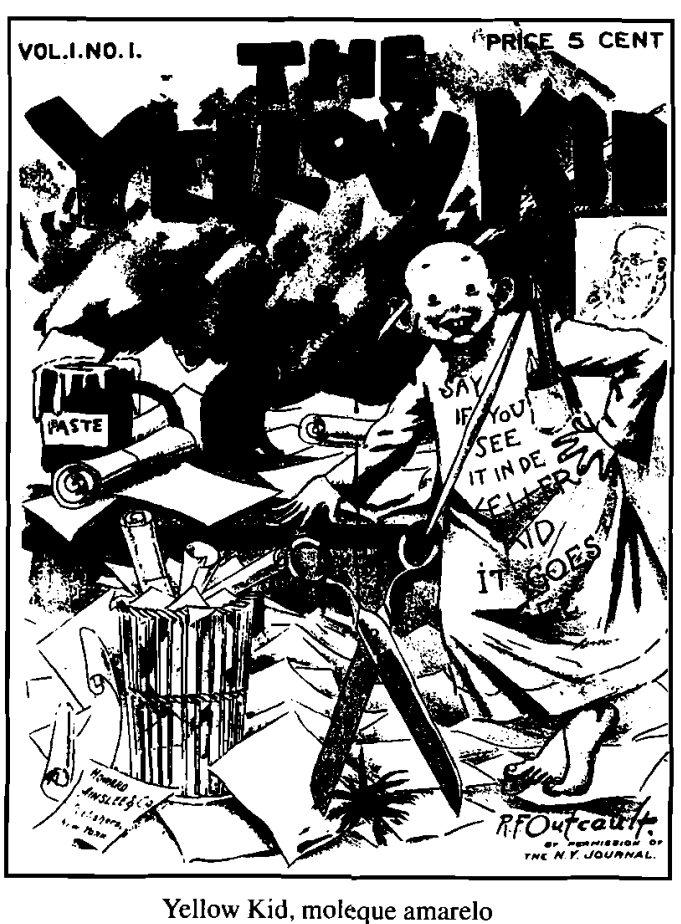

dos quadrinhos. Pulitzer, dispondo de largos recursos para o experimento, aceitou. Mas os melhores talentos dos comics, na época, já estavam contratados pelos periódicos Judge, Puck e Life, quando, então, seguindo os conselhos de Roy L. McCardell, foi contratado o artista Richard Felton ${ }^{5}$ Outcault. Graduado pela Universidade de McMiken, em Cincin- nati, estudou arte em Paris e tinha um pendor para o desenho humorístico. Um dos seus primeiros trabalhos fora $A$ origem de uma Nova Espécie, em 1894. Agora, para atender ao tema cômico proposto, Outcault criou o Down in Hogan's Alley, título adaptado das palavras de abertura da canção Maggie Murphy's Home.

O cenário era um bairro pobre da cidade, esquálidos cortiços, quintais cheios de cães e gatos, pessoas vulgares, vagabundos e desocupados. Uma favela do subúrbio. Personagens, os moleques de rua, um menino cabeçudo, uns sete anos, de grandes orelhas de abano, banguela, feições orientais, um sorriso malandro a correr-lhe nos lábios, mas que, de início, mal foi notado. Vestia uma camisolona suja, que Outcault frequientemente usou como suporte para o texto e as falas do cartum, pois ainda não empregava balões.

Mas o último elemento, essencial para produzir o tão desejado impacto visual nos leitores, a cor, ainda não tinha encontrado o seu lugar. Enquanto, de um lado, em princípios de 1895 , os problemas de impressão em cores já tinham sido resolvidos, de outro, o amarelo não secava bem e teimava em deixar manchas. O sucesso só aconteceu depois e acidentalmente. 
Foi quando Charles Saalberg, chefe do setor de impressão em cores, optou por uma tinta amarela graxa, de secagem rápida; pegou um desenho qualquer de Outcault e, a esmo, escolheu para teste a camisola do moleque orelhudo.

Naquele domingo, uma mancha de puro, vivo amarelo atraiu os olhares de todo mundo para o cartum de Outcault. O Yellow Kid tinha nascido! "e com ele o comic strip, a mais autêntica forma de arte americana, que agora é lida por mais de 200 milhões de pessoas todos os dias, cerca de 7 bilhões por ano, tornando o quadrinhista o profissional gráfico mais amplamente lido e visto no mundo..."6 e, nos Estados Unidos, o mais bem pago.

Era um grande quadro de página inteira. Emoldurava um desenho atraente: numa grande cena complexa, de ricas cores, os pobres guris do bando do Hogan's Alley, anônimos todos, revivem acrobracias de circo; as paredes do beco ecoam algazarra, berros, falas, slogans de protesto rabiscados nos muros, nas tabuletas, na camisola do chinezinho moleque, agora de esplendoroso amarelo, arrebatando, irresistível, a atenção de todos os leitores, a construção do mito.

Deslumbrados ainda pela narração do apoteótico aparecimento do Yellow Kid, todos, todo o mundo passou a aceitá-lo como a primeira personagem dos comics. E, em decorrência, que foram os americanos os primeiros, os "inventores" da linguagem do novo sistema narrativo iconográfico, ou tout court, da história em quadrinhos, que todos também se esforçam, hoje, para coroá-la com o título de "nona arte".
É o que confirma Jerry Robinson, e enfaticamente: "This cartoon has the essential criteria to credit it with being the first comic strip (Este cartum preenche os critérios essenciais para ser considerado a primeira tira de humor)"7.

\section{A HISTÓRIA DA HISTÓRIA EM QUADRINHOS}

O fantástico e surpreendente desta afirmação é a maneira extremamente fácil por que todo mundo passa ingênuo e deslumbrado de um conceito para o outro, sem o menor arremedo de questionamento. Quando um oceano separa os significados dos vocábulos Yellow Kid e comics, a mera proximidade deles na frase induz a conclusões muito além do que dizem. De fato, na frase acima, camuflada na naturalidade da afirmação, descobre-se a ufania própria do americano que se julga sempre o primeiro, se não o dono do mundo, e, mais, que o Menino Amarelo teriạ sido não só a primeira personagem, como também a primeira história em quadrinho, mas não fica aí. Fomos ainda levados a mais um fatal equívoco, ou dois.

É que traduzimos indevidamente o termo comic strip por história em quadrinhos. Ora, strip não é quadrinhos mas apenas um tipo de quadrinhos, a que chamamos nós, numa versão ao pé-da-letra, de tira. A tradução de comic strip por "história em quadrinhos" amplia ao infinito o significado do original inglês.

Dessa maneira, afirma-se que o Yellow Kid foi a primeira das histórias em quadrinhos, de todos os tipos e formas. 
E mais. Dizendo "primeira história em quadrinhos", a palavra "história" no singular e não plural amplia o seu significado abarcando genericamente não só as muitas, todas as historinhas publicadas por aí, mas também o significado de história em quadrinhos enquanto linguagem, a linguagem própria dos quadrinhos, o sistema narrativo iconográfico, isto é, o sistema de sinais figurativos que formam um código específico da comunicação por imagens. $\dot{E}$ isso que afirmamos, portanto, quando vertemos inocentemente comic strip por "história em quadrinhos". Mais uma traição, armadilha armada por nós mesmos, em nossa própria tradução brasileira.

$E$ ainda mais. Onde Robinson fez ponto-final, nós, não satisfeitos com traduzir mal comic strip, compulsivamente, fascinados ainda pelo primazia da revelação, continuamos a frase e sacramentamos o dogma: o Menino Amarelo foi a primeira história em quadrinhos... do mundo!

Passamos a afirmar muito mais do que está na superfície do que ele disse. Exaltamos agora, boquiabertos, nada menos que os "inventores", os primeiros, no mundo. Passamos a admitir que os americanos é que foram os criadores, dotados do poder divino de tirar do nada um novo código de comunicação através da imagem, o sistema narrativo iconográfico, ou, simplesmente, que fotória em quadrinhos; tudo o que veio antes, toda a copiosa produção européia, Tôpffer, Nadar, Gavarni, Cham, Doré, Busch, Travié, Robbida, Caran d'Ache, incluindo o nosso Agostini, pode ser relegado ao esquecimento ou ao lixo das varreduras diárias. Depois de seduzir os leitores de todo o mundo, o Menino Amarelo continuou ainda suas molecagens, cômicas e semânticas: ganhou a intelectualidade européia: Umberto Eco, Eveline Sullerot, Alain Resnais, Francis Lacassin, Romano Calisi, Pierre Couperie, entre muitos outros. Reunidos em Bordighera, Itália, no primeiro Congresso Internazionale dei Fumetti, em 1965, evento que se repeti- 
ria anualmente, sacramentaram, com o aval da ciência, a instituição do prêmio Yellow Kid, equivalente ao Oscar do cinema.

Os americanos sobem ao pedestal, forjado por eles e festejado por nós, tão emocionados e convictos que nem sequer ligamos para a afirmação em que Jerry Robinson, se não nega, compromete seriamente a própria versão sobre o aparecimento do Yellow Kid, quando, logo em seguida, ali mesmo no seu livro, declara o seguinte:

"O histórico debut do Yellow Kid como o primeiro comic strip tem sido datado por muitas autoridades no assunto em $16 \mathrm{de}$ fevereiro de 1896, com The Great Dog Show in M'Googan Avenue. Quando o Yellow Kid surgiu de maneira explosiva, não foi sua primeira aparição, nem era esta a primeira vez em amarelo, e não era na série do Hogan's Alley, que Outcault mudou depois. (Durante 1895, Outcault experimentou vários locais, como Riley's Pound, Coney Island, Casey's Alley e Shantytown, enquanto moldava o conceito básico e a personagem.)"8.

Para pôr ordem nas datas e cores, e atenuar a confusão armada por Robinson, e aproveitando sua própria pesquisa, será eficaz mostrar quantas vezes o travesso Moleque apareceu no jornal, rindo sempre em várias cores até ostentar o seu sorriso amarelo, sempre entre o satânico e o angelical:

- em 5 de maio de 1885, de camisola AZUL, At the Circus in Hogan's Alley (No circo de Hogan's Alley);

- em 7 de julho de 1895, ainda de AZUL, em The Day After "The Glorious Fourth" Down in Hogan's Alley;

- em 15 de dezembro de 1895, de bolinhas VERMELHAS, em The Merry Xmas; e, finalmente,
- em 5 de janeiro de 1896, de atraente AMARELO, em Golf - The Great Society Sport as Played in Hogan's Alley (Golfe - o esporte da alta sociedade da maneira como é jogado na Hogan's Alley), quando então foi batizado pelo sucesso e pelos fanáticos leitores de Yellow Kid e

- em 16 de fevereiro de 1896, em The Great Dog Show in M'Googan Avenue, de agora em diante sempre de AMARELO.

Curiosamente, é essa a edição que é tida como o debut glorioso do endiabrado guri. A 17 de maio de 1896, foi publicada a última edição desenhada por Outcault, que deixou o jornal, atraído pela oferta irrecusavelmente maior do New York Journal, de Hearst.

Disso se conclui que diversos cartoons (termo do próprio Jerry, não histórias, nem em quadrinhos) vieram antes no Down in Hogan's Alley, com a personagem ainda verde, não amadurecida, do Kid, o desconhecido Moleque que ainda não era Amarelo.

E Jerry Robinson, com suas últimas afirmações, instalou a confusão e, com ela, a desconfiança naquelas primeiras afirmações, tão categóricas. Moya seguiu os mesmos passos. Chega-se à estranha conclusão: nem Robinson nem os americanos sabem quando nasceram realmente os comic strips, muito menos a história em quadrinhos. Nem se o Yellow Kid era mesmo amarelo.

Do exposto ainda, fica claro que o Moleque Amarelo não foi e nem pode ser o primeiro dos comic strips, muito menos a primeira história em quadrinhos do mundo, porque, em 1895, o MOLEQUE AMARELO nem era HISTÓRIA, mas uma simples grande cena; nem era QUADRINHOS, mas um grande cartum, nem era STRIP, nem tinha BALÕES e NEM mesmo era AMARELO ! 
E porque, ainda, nada, muito menos uma nova linguagem pode ter brotado, assim, de repente, como cogumelo, acabada, com todos os elementos da técnica e do código narrativo da história em quadrinhos perfeitamente estruturados. Natura non facit saltus (A natureza não dá saltos, vai devagar), sentenciavam os romanos. Desde quando os homens deixaram a marca da palma de suas mãos nas paredes das cavernas e se puseram a traçar com o dedo figuras e entrelaçados, testemunho do seu poder criador, descobriram, deslumbrados, que podiam contar histórias com imagens. Os quadrinhos se fizeram devagar e desde sempre, dependendo dos instrumentos disponíveis em cada época. $E$ mais, os próprios americanos, é só olhar a história, já faziam quadrinhos antes de Outcault e de 95, com balão e tudo.

O fato é que o Yellow Kid não é mesmo a primeira história em quadrinhos do mundo. Jerry Robinson se vangloria de uma prioridade contestável.

\section{SUCESSO EMPRESARIAL}

O que não se pode negar, porém, é que o Yellow Kid tenha sido um primeiro sucesso empresarial sem precedentes, de venda e marchandaise, na imprensa americana e no mundo. Bem depressa haviam descoberto os pragmáticos ianques o óbvio, quadrinhos vendiam jornais, e passaram a povoar os periódicos com os daily comic strips (tiras diárias seriadas) e as sunday comic pages (tiras das páginas dominicais), passando mais tarde aos comic books (livros de tiras ou gibis) ${ }^{9}$. A fundação dos Syndicates, companhias distribuidoras, possibilitou estabele- cer um novo império americano, o da indústria cultural, e inundar o mundo com os seus heróis e, com eles, sua cultura.

O inaceitável da trama é se arvorarem os americanos em "criadores" dos comics. A mais rápida e despretensiosa mexida no baú da História descobre quadrinhos aos montes. Realmente muitas histórias já foram contadas em imagens, muito antes que aquele Moleque balbuciasse os primeiros balões de suas gags no jargão das favelas de Nova Iorque.

No início do século XIX, quando a litografia possibilitou a difusão da imagem, a imprensa periódica, jornais e revistas passaram a povoar de histórias o imaginário popular.

Seria um sem-fim de citações. Em 1811 aparecem as estampas populares do imaginário napoleônico; em 1812, Rowlandson cria o Dr. Syntax, um herói fixo, como nas HQ atuais. Em 1820, de cidade em cidade, os vendedores de livros desenrolam, diante de um público ávido de imagens, os pôsteres do primeiro imaginário popular, com história toda dividida em vinhetas, que outra coisa não era senão quadrinhos. Em 1824 , a Imagerie d'Épinal espalha por toda a França e Europa os mais diversos contos em figuras coloridas. Em 1827, Tôpffer, o professor suíço, conta em álbum as historinhas de Mr. Vieuxbois, que desenhara para seus alunos, e esboça as primeiras linhas teóricas sobre as histórias em quadrinhos, a nova forma de contar com imagens e texto. Em 1830, surge a revista La Caricature, que alinha, ao lado das ferinas charges contra o rei Luís Felipe, La Poire (O Trouxa), uma série de história em

9. As "tiras" diárias, em geral seriadas (que também não são invenção americana); as maravilhosas e feericamente coloridas "páginas dominicais" de quadrinhos; e, finalmente, os livros, álbuns ou revistas de histórias em quadrinhos ou os nossos "gibis" . 
imagens dos mais hábeis contadores, Daumier, Philippon, Cham, Grand-Ville, Gavarani e Traviés, Em 1847, Doré, com 12 anos apenas, publica o álbum Os Trabalhos de Hércules. Em 1848. Nadar, o famoso fotografo, cria, e sob encomenda de campanha eleitoral, a abjeta figura política de Monsieur Réac (Senhor Reac). Em 1859, as primeiras historias de Willelm Busch, e em 1865, scus terríveis moleques, Max und Moritz, cujas traquinagens devem ter inspirado o Yellow Kid e, bem depois. 1897. foram plagiadas nos Katzenjammer Kids americanos, nossos conhecidos Sobrinhos do Capitão.

primeira sraphic novel. Com sequências verdadeiramente cinematográficas, verdadeiro story board! E isso cm 1869! Muito tempo antes do Kid e o cinema, quase 3() anos!

Desmascarado o engodo, é bom começar a valorizar o nosso, comemorar as revistas em que brilharam bem antes os nossos quadrinhistas: os $\mathbf{9 0}$ anos do revista Tico-Tico, os 100 anos do Don Quixote, os 130 do Diabo Coxoll.

Deixar de lado a diabólica idéia de embarcar de caroma um Moleque que ainda NÃO era Amarelo, no

\section{ENTRE}

OS PIONEIROS, ÂNGELO AGOSTINI

E nessa galeria de pionciros deve-se colocar também, e muito justamente, o nosso Ângelo Agostini, porque foi um dos primeiros a fazer quadrinbos, inuito antes que Outcault rabiscasse as molecagens do seu Yellow Kid pelas favelas de Nova lorque. As Aventuras de Nhô Quim, história em muitos ca-

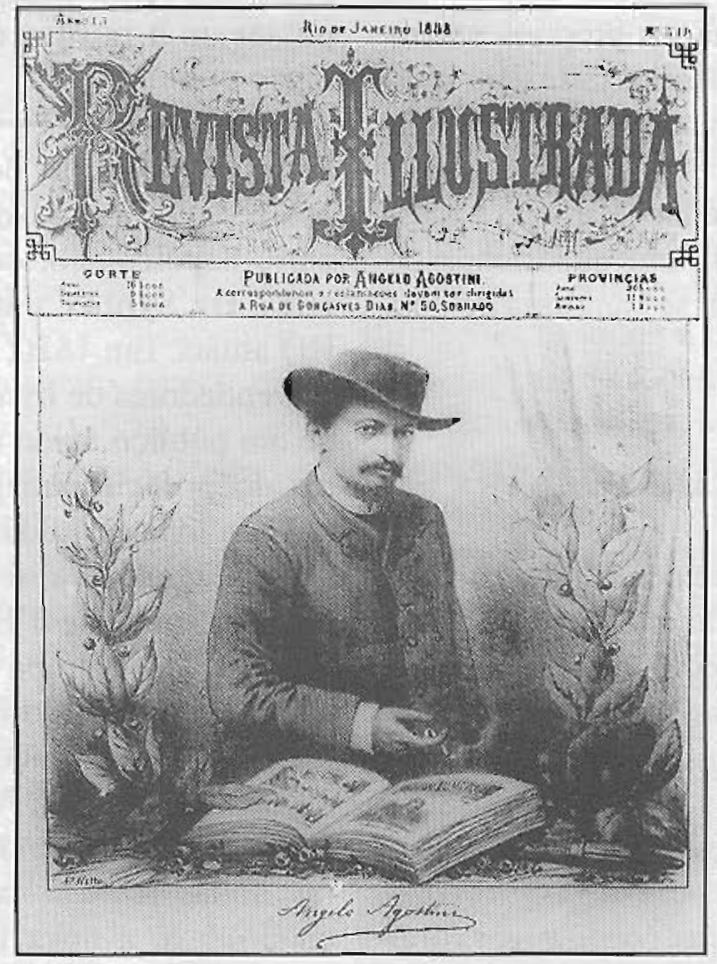

Ângelo $\Lambda$ gostini, un dos primeicos cuádrinhistas. embalo de um centenário que, parece, vem na cola dos cem anos do cinema para compensal o frasco de nào terem sido os americanos, mais uma vez, os primeiros (como teimam sempre, $\mathrm{cm}$ tudo), os inventores dessa nova arte.

Quais os ocultos interesses que se agacham solrateiros atrás desta fachada? Mostrar que a hislória deveria ser contada de outra forma? Assim, por excmplo:

1895. O Yel-

low Kid irrompe pítulos é a primeira novela-folhetim de explosivo, vitorioso na imprensa americana que se tem notícia, ou como se diz hoje, a e multiplica a tiragem do New York World

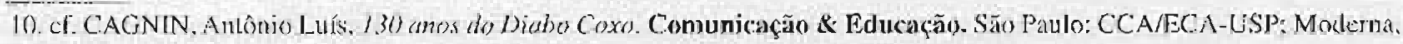

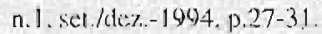


para atender ao atropelo dos leitores, ofuscados pelo brilhante e vivo amarelo; do outro lado do Atlântico, o tosco cinematógrafo de Lumière mal consegue atrair uma fila, ainda que longa, de curiosos espectadores diante do salão indiano do Grand Café, no boulevard des Capucines, em Paris.
Se, na realidade, as duas artes não nasceram juntas, não há por que tinir as taças num brinde comum. Não seria melhor esperar mais um ano? quando todas as atenções se voltariam somente para o Moleque, fruto do amadurecimento de um projeto, então ainda verde, que só em 1896 ficou Amarelo? ${ }^{11}$.
Resumo: $\mathrm{O}$ artigo analisa o aparecimento da personagem Yellow Kid do cartoon criado por Richard Felton Outcault no New York World, em 1895. Contesta, veementemente, com argumentos históricos e teóricos, que o Moleque tenha sido a primeira personagem dos comics e que os americanos tenham criado a história em quadrinhos. Entre os que o antecederam, ressalta Ângelo Agostini.

Palavras-chave: Yelow Kid, Histórias em Quadrinhos, Ângelo Agostini, cartum.

Dom Quixote e Sancho Pança, por Ângelo Agostini, no jornal Don Quixote.
Abstract: The article is about the coming out of the character Yellow Kid from the cartoon created by Richard Felton Outcault in the New World, in 1895. Based upon theoretical and historical arguments it denies that Mo-

leque (Kid) has been the first character of the comics and that the Americans have created the comic books. Among who came before him, an outstanding na$\mathrm{me}$ is Ângelo Agostini.

Key-words: Yellow Kid, comic books, Angelo Agostini, cartoons.

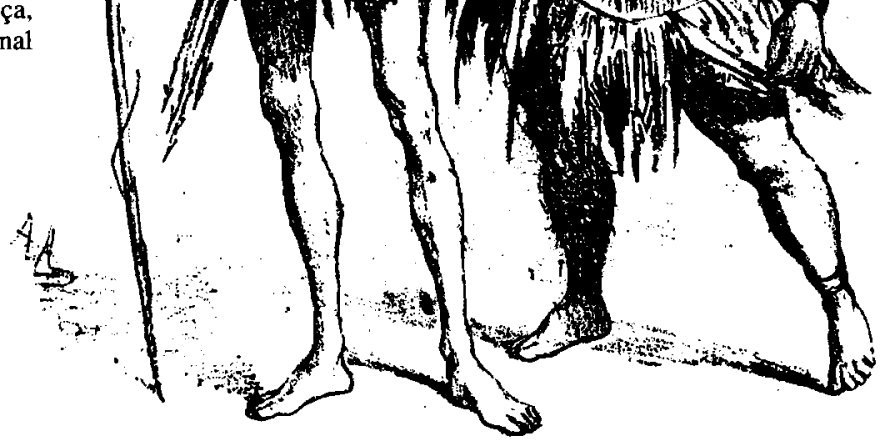

11. É o que está fazendo, neste ano de 1996, o Salão Expocomics, de Roma, e o Cartomics, de Milão, em oposiçāo ao tradicional de Luca e à exposição de Verona, realizados em novembro de 1995. 